\title{
Economic Growth and Longevity Risk with Adverse Selection
}

\author{
Ben J. Heijdra \\ Laurie S. M. Reijnders
}

CESIFO WORKING PAPER NO. 2898

CATEGORY 6: FisCAL POLICY, MACROECONOMICS AND GROWTH

DECEMBER 2009

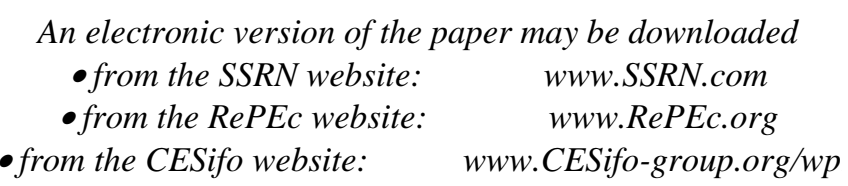




\title{
Economic Growth and Longevity Risk with Adverse Selection
}

\begin{abstract}
We study a closed economy featuring heterogeneous agents and exhibiting endogenous economic growth due to interfirm external effects. Individual agents differ in terms of their mortality profile. At birth, nature assigns a health status to each agent. Health type is private information and annuity firms can only observe an agent's age. In the presence of longevity risk, agents want to annuitize their wealth conform the classic result by Yaari (1965). In the first-best case with perfect annuities, the market would feature a separating equilibrium (SE) in which each health type obtains an actuarially fair perfect insurance. In the SE all agents are savers throughout their lives. The informational asymmetry precludes the attainment of the first-best equilibrium, however, as healthy individuals have a strong incentive to misrepresent their type by claiming to be unhealthy. Using the equilibrium concept of Pauly (1974) and Abel (1986), we prove the existence of a second-best pooling equilibrium (PE) in which individuals of all types annuitize at a common pooling rate. As the unhealthy get close to their maximum attainable age, the pooling rate prompts such individuals to become net borrowers. But borrowing would reveal their health status, so the best the unhealthy can do is to impose a borrowing constraint on themselves during their autumn years. Using a plausibly calibrated version of the model we find that the growth- and welfare effects of PE versus SE are rather small, whilst those of PE versus no annuities at all (NAE) are rather large. An imperfect insurance is better than no insurance at all, both at the microeconomic and at the macroeconomic level.
\end{abstract}

JEL-Code: D52, D91, E10, J20.

Keywords: annuity markets, adverse selection, endogenous growth, overlapping generations, demography.

Ben J. Heijdra

Faculty of Economics and Business

University of Groningen

P.O. Box 800

NL - 9700 AV Groningen

The Netherlands

info@heijdra.org
Laurie S. M. Reijnders

Faculty of Economics and Business

University of Groningen

P.O. Box 800

NL - 9700 AV Groningen

The Netherlands

lauriereijnders@gmail.com

December 21, 2009 


\section{Introduction}

Economic theory suggests that life annuities are very attractive insurance instruments in the presence of longevity risk. This result was first articulated in the seminal paper by Yaari (1965) and was recently recast in a much more general setting by Davidoff, Brown, and Diamond (2005). The intuition behind this result is not very difficult: annuities insure against the risk of outliving one's assets.

Over the last few decades, however, more and more evidence has been unearthed hinting at the existence of an annuity puzzle: a rather robust fact of life is that in reality very few individuals purchase life annuities despite their theoretical attractiveness. Friedman and Warshawsky (1990, pp. 136-7) give the following potential explanations for the low participation in private annuity markets. First, individuals may want to leave bequests to their offspring. Second, individuals may hold other types of annuities, e.g. in the form of social security and private pensions (social annuities). Third, private annuities may be priced unattractively because of transactions costs and taxes, excessive monopoly profits earned by annuity firms, and adverse selection. ${ }^{1}$ A fourth explanation is that family risk sharing may act an as incomplete annuity market, a result first proposed by Kotlikoff and Spivak (1981).

In this paper we restrict attention to the adverse selection channel. ${ }^{2}$ Intuitively adverse selection arises because individuals who believe themselves to be healthier than average are more likely to buy annuities, i.e. the high-risk types are overrepresented in the clientele of annuity firms and annuity pricing cannot be based on average population mortality.

The objective of our paper is to study the growth and welfare implications of adverse selection effects in the annuity market. Our model has the following key features. First, we postulate a simple general equilibrium model of a closed economy featuring endogenous growth. Second, we assume that the economy is populated by overlapping generations of heterogeneous finitely-lived agents. Individual agents know their own death probability process, but annuity firms cannot observe an agent's health type (neither directly nor indirectly). The mortality process is modeled realistically and closely tracks existing demographic data. In

\footnotetext{
${ }^{1}$ Following the initial research by Friedman and Warshawsky (1988, 1990), a large subsequent literature has emerged. See for example Mitchell et al. (1999), Finkelstein and Poterba (2002, 2004), and Finkelstein et al. (2009).

${ }^{2}$ Heijdra and Mierau (2009) study the general equilibrium implications of imperfect annuities under the excess monopoly profit interpetation.
} 
the core model we distinguish two types of agents, namely healthy and unhealthy, and we assume that their respective population shares are constant.

Third, we assume perfectly competitive annuity markets, with firms offering linear annuity contracts, cf. Pauly (1974) and Abel (1986). Under this equilibrium concept the insurer can only choose the price of the annuity and cannot achieve complete market separation. ${ }^{3}$

The main findings of our analysis are as follows. First, if health status were observable or could be "credibly signalled" to insurers, then there would be a separating equilibrium (SE) in which each health type would get actuarially fair perfect insurance. We consider the case of a patient economy in which all types would be net savers during life. In the SE, however, healthy individuals have a huge incentive to misrepresent their health status ("by cheating" and claiming to be a low-risk type) thus destroying market separation. The SE is thus a hypothetical case acting as a benchmark.

Second, with health being an unobservable attribute, perfect competition in the annuity market will result in a pooling equilibrium (PE). The equilibrium pooling rate is an assetweighted average of individual mortality rates, a result first derived in a partial equilibrium context by Sheshinski (2008). In the PE, the unhealthy (low-risk types) get a less than actuarially fair rate (as stressed in the literature), but the healthy (high-risk types) get a better than actuarially fair rate. This result shows that Friedman and Warshawsky (1990, pp. 147-152) only consider one side of the coin by restricting attention to individuals facing less than actuarially fair annuity returns (see their Tables V and VI). In contrast, in our general equilibrium model the healthy annuitants benefit for part of their life from the presence of unhealthy annuitants.

Third, in the PE the unhealthy encounter a "self-imposed" borrowing constraint if they live long enough. Intuitively, as the unhealthy get close to their maximum attainable age, the pooling rate prompts such individuals to become net borrowers. But borrowing would reveal their health status, so the best the unhealthy can do is to impose a borrowing constraint on themselves during their autumn years. It must be stressed that this asset depletion result is not exogenously imposed (as in the partial equilibrium studies of Friedman and Warshawsky (1990, p. 147) and Walliser (2000, pp. 378-9)) but follows from the internal logic of the

\footnotetext{
${ }^{3}$ An alternative equilibrium concept that can be used to deal with adverse selection is the one suggested by Rothschild and Stiglitz (1976). See Eichenbaum and Peled (1987) for an application of the Rothschild-Stiglitz concept. See Walliser (2000, pp. 376-7) and below for a defense of the linear pricing assumption.
} 
model. ${ }^{4}$ Hence, our model yields a consistent explanation why not everybody annuitizes in a general equilibrium model with risk pooling.

Fourth, for a plausibly calibrated version of the model we find that (a) the SE is only slightly better in welfare terms than the $\mathrm{PE}$, and (b) the $\mathrm{PE}$ is vastly better than no-annuities equilibrium (NAE) in which all health types are confronted with the possibility of asset depletion at relative young ages. Hence, imperfect longevity insurance is better than no insurance at all.

Our paper is most closely related to Abel (1986) and Walliser (2000). Both of these papers use the linear annuity pricing concept adopted by us. Abel (1986) presents a simple two-period general equilibrium exogenous growth model. The model features privately known longevity risk, two health types, and adverse selection and also allows for bequests. In his partial equilibrium model, Walliser (2000) extends Abel (1986) to include 75 periods and simultaneous health and income heterogeneity. As was mentioned above, he exogenously imposes a non-negativity constraint on annuity holdings.

The structure of our paper is as follows. Section 2 presents the continuous-time model. Section 3 states the key informational assumptions and studies the balanced growth path for the (hypothetical) separating equilibrium and the pooling equilibrium. This section also presents a plausible calibration and visualization of the different equilibria as well as their welfare properties. Section 4 restates the main results and presents some possible extensions. The paper also contains two brief mathematical appendices containing the proofs of the two propositions stated in the main text.

\footnotetext{
${ }^{4}$ In particular, our result follows from the fact that (a) there are only two health types, (b) all individuals are life-cycle savers in the SE, and (c) the life-insured SE borrowing rate is punitively high. In future research we plan to study the case with more than two health types and investigate the simultaneous existence of pooling equilibria in the annuity and life-insurance markets.
} 


\section{Model}

\subsection{Consumers}

\subsubsection{Individual behaviour}

Individuals differ according to their health status acquired at birth. From the perspective of birth, the expected remaining lifetime utility function of a health type $j$ individual is given by:

$$
\Lambda_{j}(v, v)=\int_{v}^{v+\bar{D}_{j}} \ln \bar{c}_{j}(v, \tau) \cdot e^{-\rho(\tau-v)-M_{j}(\tau-v)} d \tau
$$

where $v$ is the birth date, $\bar{D}_{j}$ is the maximum attainable age for this type of agent, $\bar{c}_{j}(v, \tau)$ is consumption, $\rho$ is the pure rate of time preference, and $e^{-M_{j}(\tau-v)}$ is the probability that the agent is still alive at some future time $\tau(\geq v) .{ }^{5}$ Here, $M_{j}(\tau-v) \equiv \int_{0}^{\tau-v} \mu_{j}(s) d s$ stands for the cumulative mortality rate and $\mu_{j}(s)$ is the instantaneous mortality rate of an agent of age $s$, where $0 \leq s \leq \bar{D}_{j}$. This rate is strictly increasing in age, $\mu_{j}^{\prime}(s)>0$ and $\mu_{j}^{\prime \prime}(s)>0$, and features $\lim _{s \rightarrow \bar{D}_{j}} \mu_{j}(s)=+\infty$. To keep things simple, the felicity function is assumed to be logarithmic, implying a unitary intertemporal substitution elasticity.

The agent's budget identity is given by:

$$
\dot{\bar{a}}_{j}(v, \tau)=\left[r+p_{j}(\tau-v)\right] \cdot \bar{a}_{j}(v, \tau)+w(\tau)-\bar{c}_{j}(v, \tau)
$$

where $\bar{a}_{j}(v, \tau)$ is real financial wealth, $r$ is the interest rate (a constant, see below), $w(\tau)$ is the wage rate. In the spirit of Yaari (1965), we assume that agents can purchase annuities to insure against longevity risk. Without a bequest motive, financial wealth is fully annuitized so $\bar{a}_{j}(v, \tau)$ is also the agent's demand for annuities. Since an agent's age at time $\tau$ is directly observable to the insurer, the net return on such annuities, $p_{j}(\tau-v)$, depends on it. Labour supply is exogenous and each agent supplies a single unit of labour throughout life, i.e. we abstract from retirement.

At time $v$, the agent chooses paths for consumption and financial assets in order to maximize lifetime utility (1) subject to the flow budget identity (2) and a solvency condition, taking as given its initial level of financial assets $\bar{a}_{j}(v, v)=0$. In the absence of borrowing

\footnotetext{
${ }^{5}$ For a detailed derivation of the lifetime utility function in the presence of mortality risk, see Heijdra and Romp (2008, pp. 91-92).
} 
constraints, the agent's optimal plans for $v \leq t \leq v+\bar{D}_{j}$ are fully characterized by:

$$
\begin{gathered}
\frac{\dot{\bar{c}}_{j}(v, t)}{\bar{c}_{j}(v, t)}=r+p_{j}(t-v)-\mu_{j}(t-v)-\rho \\
\bar{c}_{j}(v, v)=\frac{\int_{v}^{v+\bar{D}_{j}} w(\tau) \cdot e^{-r(\tau-v)-P_{j}(\tau-v)} d \tau}{\int_{v}^{v+\bar{D}_{j}} e^{-\rho(\tau-v)-M_{j}(\tau-v)} d \tau} \\
\bar{a}_{j}(v, t) \cdot e^{-r(t-v)-P_{j}(t-v)}=\int_{v}^{t} w(\tau) e^{-r(\tau-v)-P_{j}(\tau-v)} d \tau-\bar{c}_{j}(v, v) \int_{v}^{t} e^{-\rho(\tau-v)-M_{j}(\tau-v)} d \tau,(5)
\end{gathered}
$$

where $P_{j}(\tau-v) \equiv \int_{0}^{\tau-v} p_{j}(s) d s$ is the cumulative net annuity return factor. Equation (3) is the 'consumption Euler equation', relating the optimal time profile of consumption to the difference between the annuity rate of interest $\left(r+p_{j}(\tau-v)\right)$ and the total rate of felicity discounting due to impatience and mortality $\left(\rho+\mu_{j}(\tau-v)\right)$. Equation (4) shows that consumption at birth is proportional to human wealth (the numerator), consisting of the annuitized value of wages. The propensity to consume (one over the denominator) depends on the 'effective' discount rate facing the consumer. Finally, the planned path of financial wealth is defined in (5). It is easy to see that financial assets are zero at birth and at the date of certain death, $\bar{D}_{j}$. The exact form of the wealth profile depends on the specific type of equilibrium on the annuity market (see Section 3).

Below we encounter equilibria in which type $j$ agents experience a binding borrowing constraint from age $\bar{S}_{j}$ onward. In that case equations (3) and (5) are valid only for $0 \leq$ $t-v \leq \bar{S}_{j}, \bar{a}_{j}(v, t)=0$ and $\bar{c}_{j}(v, t)=w(t)$ for $\bar{S}_{j} \leq t-v \leq \bar{D}_{j}$, and $\bar{S}_{j}$ replaces $\bar{D}_{j}$ in $(4)$.

\subsubsection{Demography}

We allow for a non-zero rate of population growth but impose that the relative population proportion of people of different health types is constant. Since health groups are distinguished by their mortality process, this requirement furnishes the following condition:

$$
\beta_{j} \cdot \int_{0}^{\bar{D}_{j}} e^{-n s-M_{j}(s)} d s=1,
$$

where $\beta_{j}$ is the crude birth rate of type $j$ cohorts, and $n$ is the growth rate of the population. For a given value of $n$ and a given mortality process $M_{j}(s)$, equation (6) defines the coherent solution for $\beta_{j}$. The newborn cohort of type $j$ at time $v$ is given by $L_{j}(v, v)=\pi_{j} \beta_{j} L(v)$ where $L(v)$ is the total population at time $v$ and $\pi_{j}$ is the fraction of type $j$ people in the population. The average mortality rate for type $j$ people is given by 
$\bar{\mu}_{j} \equiv\left[\int_{t-\bar{D}_{j}}^{t} \mu_{j}(t-v) L_{j}(v, t) d v\right] / L_{j}(t)=\beta_{j}-n$. Finally, the relative cohort size of type $j$ agents of age $t-v$ evolves according to:

$$
l_{j}(v, t) \equiv \frac{L_{j}(v, t)}{L(t)}= \begin{cases}\beta_{j} \pi_{j} e^{-n(t-v)-M_{j}(t-v)} & \text { for } 0 \leq t-v \leq \bar{D}_{j} \\ 0 & \text { for } t-v>\bar{D}_{j}\end{cases}
$$

Intuitively, the relative size of the type $j$ cohort declines with age because the aggregate population grows over time (first cause) and cohort members die (second cause).

\subsubsection{Aggregate household behaviour}

Armed with equation (7), it is possible to compute per capita values for consumption and assets. We restrict attention to the balanced growth path along which wages grow at a constant exponential rate, $g$. It follows that:

$$
w(t)=w(v) \cdot e^{g(t-v)} .
$$

Allowing for a borrowing constraint at age $\bar{S}_{j}$ and using (8) we find that per capita consumption of type $j$ agents, $c_{j}(t) \equiv \int_{t-\bar{D}_{j}}^{t} l_{j}(v, t) \bar{c}_{j}(v, t) d v$, can be written as:

$$
\frac{c_{j}(t)}{w(t)}=\beta_{j} \pi_{j} \cdot\left[\frac{\bar{c}_{j}(v, v)}{w(v)} \int_{0}^{\bar{S}_{j}} e^{(r-n-g-\rho) s-2 M_{j}(s)+P_{j}(s)} d s+\int_{\bar{S}_{j}}^{\bar{D}_{j}} e^{-n s-M_{j}(s)} d s\right] .
$$

By aggregating over all health types, per capita consumption is obtained, i.e. $c(t) \equiv \sum_{j} c_{j}(t)$.

In a similar fashion we find that per capita asset holdings of type $j$ agents, $a_{j}(t) \equiv$ $\int_{t-\bar{D}_{j}}^{t} l_{j}(v, t) \bar{a}_{j}(v, t) d v$, evolves over time according to:

$$
\dot{a}_{j}(t)=(r-n) a_{j}(t)+\pi_{j} w(t)-c_{j}(t)+\int_{t-\bar{D}_{j}}^{t}\left[p_{j}(t-v)-\mu_{j}(t-v)\right] l_{j}(v, t) \bar{a}_{j}(v, t) d v .
$$

It follows that per capita assets, $a(t) \equiv \sum_{j} a_{j}(t)$, satisfy the following differential equation:

$$
\dot{a}(t)=(r-n) a(t)+w(t)-c(t)+\Xi(t)
$$

where $\Xi(t)$ is defined as follows:

$$
\Xi(t) \equiv \sum_{j} \int_{t-\bar{D}_{j}}^{t} l_{j}(v, t) \cdot\left[p_{j}(t-v)-\mu_{j}(t-v)\right] \cdot \bar{a}_{j}(v, t) d v .
$$




\section{$2.2 \quad$ Firms}

In the spirit of Romer (1989), we assume that there exist strong external effects operating between private firms in the economy. The economy features a large and fixed number, $N_{0}$, of identical, perfectly competitive firms. The technology available to firm $i$ is given by:

$$
Y_{i}(t)=\Omega(t) K_{i}(t)^{\varepsilon} L_{i}(t)^{1-\varepsilon}, \quad 0<\varepsilon<1,
$$

where $Y_{i}(t)$ is output, $K_{i}(t)$ is the capital input, $L_{i}(t)$ is the labour input, and $\Omega(t)$ represents the general level of factor productivity which is taken as given by individual firms. The competitive firm hires factors of production according to the following marginal productivity conditions:

$$
\begin{aligned}
w(t) & =(1-\varepsilon) \Omega(t) k_{i}(t)^{\varepsilon}, \\
r(t)+\delta & =\varepsilon \Omega(t) k_{i}(t)^{\varepsilon-1},
\end{aligned}
$$

where $k_{i}(t) \equiv K_{i}(t) / L_{i}(t)$ is the capital intensity. The rental rate on each factor is the same for all firms, i.e. they all choose the same capital intensity and $k_{i}(t)=k(t)$ for all $i=1, \cdots, N_{0}$. This feature enables us to aggregate the microeconomic relations to the macroeconomic level.

Generalizing the insights of Saint-Paul (1992, p. 1247) and Romer (1989) to a non-constant population, we assume that the inter-firm externality takes the following form:

$$
\Omega(t)=\Omega_{0} k(t)^{1-\varepsilon},
$$

where $\Omega_{0}$ is a positive constant, $k(t) \equiv K(t) / L(t)$ is the economy-wide capital intensity, $K(t) \equiv \sum_{i} K_{i}(t)$ is the aggregate capital stock, and $L(t) \equiv \sum_{i} L_{i}(t)$ is aggregate employment. According to (16), total factor productivity depends positively on the economy-wide capital intensity, i.e. if an individual firm $i$ raises its capital intensity, then all firms in the economy benefit somewhat as a result because the general productivity indicator rises for all of them. Using (16), equations (13)-(15) can now be rewritten in aggregate terms:

$$
\begin{aligned}
Y(t) & =\Omega_{0} K(t), \\
w(t) L(t) & =(1-\varepsilon) Y(t), \\
r(t) & =r=\varepsilon \Omega_{0}-\delta,
\end{aligned}
$$


where $Y(t) \equiv \sum_{i} Y_{i}(t)$ is aggregate output and we assume that capital is sufficiently productive, i.e. $\varepsilon \Omega_{0}>n+\delta$. The macroeconomic technology is linear in the capital stock and the interest rate is constant and exceeds the rate of population growth.

\section{Balanced growth path}

In this section we study the steady-state features of the general equilibrium growth model. We adopt the following set of assumptions regarding the market for annuities.

Assumption (A1) The annuity market is perfectly competitive. A large number of firms offer annuity contracts to individuals. Firm entry and exit is unrestricted.

Assumption (A2) Annuity firms do not use up any real resources.

Assumption (A3) The annuitant's health status is private information and cannot be observed by the annuity companies. Annuity firms know all the features of the mortality process of each health group.

Assumption (A4) The annuitant's age is public information and can thus be observed by the annuity companies.

Assumption (A5) Annuitants can buy multiple annuities for different amounts and from different annuity firms. Individual annuity firms cannot observe an annuitant's holdings with their competitors.

The existence of a pooling equilibrium depends critically on the joint validity of assumptions (A3) and (A5). Under these assumptions, annuity firms cannot distinguish between healthy and unhealthy annuitants. Even though healthy annuitants are richer than unhealthy annuitants (both in reality and in our model), and thus feature a higher total demand for annuities, they can nevertheless hide this fact by buying small amounts from several companies.

By assumption (A4), annuity firms can observe each annuitant's age, $u$, so in the pooling equilibrium there is a single pooling rate, $\bar{p}(u)$, for healthy and unhealthy annuitants of age $u$. There is market segmentation in the sense that the annuity market consists of separate submarkets for each age group or cohort. By assumption (A1), the expected profit in each submarket is zero. With large cohorts, probabilities and frequencies coincide so that actual 
profit in each submarket is also zero. Finally, assumption (A2) ensures that there is no loading factor on annuities.

Before turning to a detailed study of the pooling equilibrium in subsection 3.2 , we first discuss the benchmark case for which assumption (A3) is violated and annuity firms can observe each annuitant's health type. This is the separating equilibrium studied in subsection 3.1.

Although the model has been constructed to allow for an arbitrarily large number of health types, we simplify the discussion from here on by distinguishing only two health groups, namely healthy agents $(j=H)$ and unhealthy agents $(j=U)$. We furthermore adopt the mortality process of Boucekkine et al. (2002) which takes the following form:

$$
e^{-M_{j}(s)} \equiv \frac{\eta_{0}-e^{\eta_{1 j} s}}{\eta_{0}-1}, \quad 0 \leq s \leq \bar{D}_{j} \equiv \frac{1}{\eta_{1 j}} \ln \eta_{0},
$$

where $\eta_{0}>1$ and $\eta_{1 j}>0$. The implied instantaneous mortality rate for this demography is given by:

$$
\mu_{j}(s) \equiv M_{j}^{\prime}(s)=\frac{\eta_{1 j} e^{\eta_{1 j} s}}{\eta_{0}-e^{\eta_{1 j} s}} .
$$

This mortality process satisfies the assumption made in the text below equation (1). To capture the relative health status of the two groups we set $\eta_{1 U}=\theta \eta_{1 H}$ with $\theta>1$. This parameterization implies that the maximum attainable age for the healthy exceeds the one for the unhealthy, i.e. $\bar{D}_{H}=\theta \bar{D}_{U}$. Furthermore, the instantaneous mortality rate is uniformly higher for the unhealthy, i.e. $\mu_{U}(u)>\mu_{H}(u)$ for $0 \leq u \leq \bar{D}_{U}$. See Figure 1 below for a visualization of these results. In that figure and throughout the paper an "economic age" of $u=0$ corresponds to a biological age of 18 years, i.e. we assume that independent economic decision making starts at the age of maturity (see also below).

\subsection{Separating equilibrium}

If annuity firms are able to observe an annuitant's health type, then they will set the net return on annuities equal to the relevant mortality rate, $p_{j}(\tau-v)=\mu_{j}(\tau-v)$ and thus also $P_{j}(\tau-v)=M_{j}(\tau-v)$. It follows from (3), (5), and (8) that:

$$
\begin{aligned}
\frac{\dot{\bar{c}}_{j}(v, v+u)}{\bar{c}_{j}(v, v+u)} & =r-\rho, \\
\frac{\bar{a}_{j}(v, v+u)}{w(v)} \cdot e^{-r u-M_{j}(u)} & =\int_{0}^{u} e^{-(r-g) s-M_{j}(s)} d s-\frac{\bar{c}_{j}(v, v)}{w(v)} \int_{0}^{u} e^{-\rho s-M_{j}(s)} d s,
\end{aligned}
$$


(a) surviving fraction

$$
e^{-M_{j}(u)}
$$

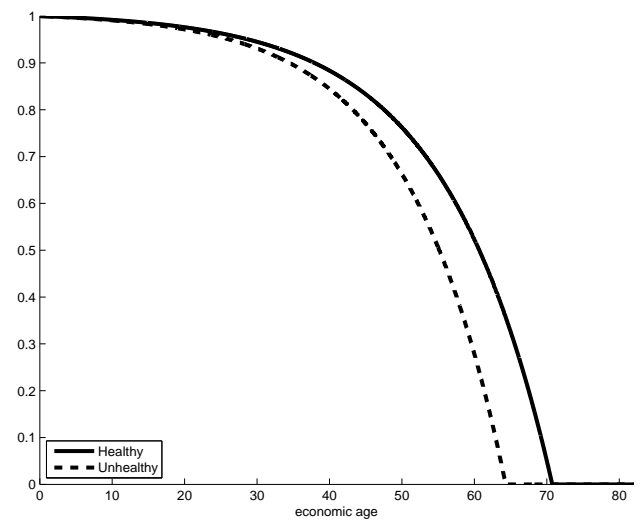

(b) instantaneous mortality rate

$$
\mu_{j}(u)
$$

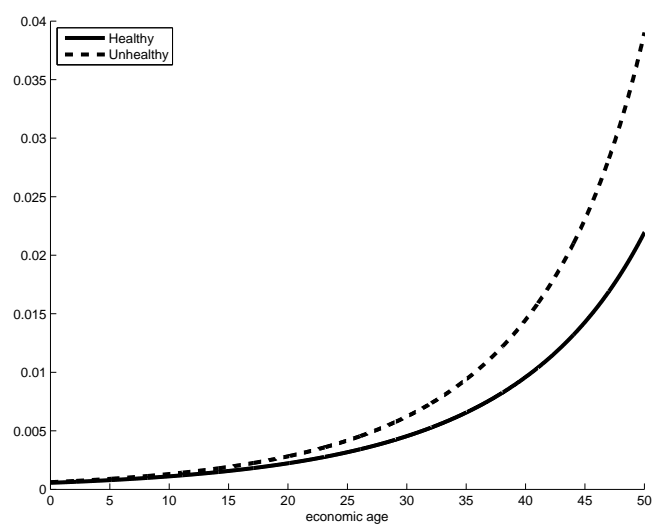

Figure 1: Demographics

where $u \equiv t-v$ is the agent's age at time $t$. The instantaneous mortality rate does not feature in (22) because households fully insure against the unpleasant effects of lifetime uncertainty (Yaari, 1965). It is easy to see from (23) that financial assets are strictly positive throughout the agent's life.

Proposition 1. Consider the separating equilibrium (SE) in which annuity firms can observe the health type of annuitants. Provided the growth-corrected interest rate exceeds the pure rate of time preference, $r-g>\rho$, agents of all health types are net savers throughout life, i.e. $\bar{a}_{j}(v, v)=\bar{a}_{j}\left(v, v+\bar{D}_{j}\right)=0$ and $\bar{a}_{j}(v, v+u)>0$ for $0<u<\bar{D}_{j}$.

Proof. See Appendix A.

The key equations of the separating general equilibrium model are collected in Table 1. The expressions in (T1.1) follow in a straightforward fashion from (4) and (8) above. Equation (T1.2) is obtained by setting $\bar{S}_{j}=\bar{D}_{j}$ in (9) and noting the definition of $c(t)$. The growth expression, equation (T1.3), follows readily from (11) by noting two features of the model. First, since claims on the capital stock are the only financial assets available, capital market equilibrium ensures that $a(t)=k(t)$. Second, since $p_{j}(t-v)=\mu_{j}(t-v)$ it follows from (12) that $\Xi(t)=0$ for all $t$. There is no redistribution between health groups because each group 
Table 1: Balanced growth in the separating equilibrium

(a) Microeconomic relationships:

$$
\frac{\bar{c}_{j}(v, v)}{w(v)}=\frac{\int_{0}^{\bar{D}_{j}} e^{-(r-g) s-M_{j}(s)} d s}{\int_{0}^{\bar{D}_{j}} e^{-\rho s-M_{j}(s)} d s}, \quad j \in\{H, U\}
$$

(b) Macroeconomic relationships:

$$
\begin{aligned}
\frac{c(t)}{w(t)} & =\sum_{j \in\{H, U\}} \beta_{j} \pi_{j} \cdot \frac{\bar{c}_{j}(v, v)}{w(v)} \cdot \int_{0}^{\bar{D}_{j}} e^{(r-n-g-\rho) s-M_{j}(s)} d s \\
g & \equiv \frac{\dot{k}(t)}{k(t)}=r-n+\left[1-\frac{c(t)}{w(t)}\right] \cdot \frac{w(t)}{k(t)} \\
\frac{w(t)}{k(t)} & =(1-\varepsilon) \Omega_{0}
\end{aligned}
$$

Notes. (a) Endogenous are $\bar{c}_{j}(v, v) / w(v), g, w(t) / k(t)$, and $c(t) / w(t)$. (b) There are two types of agents, healthy (subscript $H$ ) and unhealthy (subscript $U$ ). (c) $M_{j}(s), \bar{D}_{j}, \beta_{j}$, and $\pi_{j}$ stand for, respectively, the cumulative mortality rate at age $s$, the maximum attainable age, the crude birth rate, and the population fraction of type $j$ agents. $n$ is the population growth rate, $\rho$ is the rate of time preference, $\varepsilon$ is the capital coefficient in the technology, and $\Omega_{0}$ is the scale factor in the technology. The interest rate is $r \equiv \varepsilon \Omega_{0}-\delta$, where $\delta$ is the depreciation rate of capital.

receives the net return befitting its mortality profile. Finally, equation (T1.4) is obtained by combining equations (17)-(18).

The model features a two-way interaction between the microeconomic decisions and the macroeconomic outcomes. On the one hand, for a given macroeconomic growth rate $g$, (T1.1) determines scaled consumption at birth for the two health types. On the other hand, for given values of scaled consumption at birth, (T1.2)-(T1.4) yield general equilibrium solutions for $c(t) / w(t), g$, and $w(t) / k(t)$.

In order to visualize the properties of the model and to quantify the effects of informational asymmetries and adverse selection on the general equilibrium allocation, we calibrate the model in a plausible fashion. We take the demographic parameters for the healthy group from Heijdra and Mierau (2009). They use data from biological age 18 onward for the cohort born in the Netherlands in 1960 and estimate the parameters appearing in (20). This gives 
the following estimates (with t-statistic in brackets): $\eta_{0}=122.643(11.14)$ and $\eta_{1 H}=0.068$ (48.51). It follows that $\bar{D}_{H}=70.754$. We furthermore assume that $\theta=1.1$, so that $\eta_{1 U}=$ 0.075 and $\bar{D}_{U}=64.322$. There is a substantial difference between the maximum attainable age for the two health types of about 6.432 years. Figure 1 shows the key features of the mortality processes of the two health types.

We assume that the rate of population growth is one percent per annum $(n=0.01)$. In view of the demographic equilibrium condition (6) and the demographic features discussed above, this gives crude birth rates of $\beta_{H}=0.0234$ and $\beta_{U}=0.0251$. The capital depreciation rate is ten percent per annum $(\delta=0.10)$, the interest rate is six percent $(r=0.06)$, and the rate of time preference is three and a half percent $(\rho=0.035)$. We postulate that in the (hypothetical) separating equilibrium (SE) the economy features a steady-state growth rate of two percent per annum $(g=0.02)$. In the core case, we assume equal fractions of healthy and unhealthy individuals in the population, i.e. $\pi_{H}=\pi_{U}=\frac{1}{2}$. We use the efficiency parameter of capital as a calibration parameter and find $\varepsilon=0.1744$. It follows that the constant in the production function is equal to $\Omega_{0}=(r+\delta) / \varepsilon=0.9174$. In summary, the SE has the following features: $\bar{c}_{H}(v, v) / w(v)=0.9094, \bar{c}_{j}(v, v) / w(v)=0.9139, c(t) / w(t)=1.0396$, $g=2$, and $w(t) / k(t)=0.7574$. For convenience these values are restated in column (a) in Table 2 .

Figure 2 visualizes a number of life-cycle features of the SE. Panel (a) depicts the age profiles for scaled consumption. The paths for the two health types are virtually on top of each other. As is clear from (22), consumption grows exponentially with age at a rate equal to $r-\rho$. Panel (b) of Figure 2 shows the life-cycle pattern of scaled cohort assets (individual assets display a rather similar pattern). As is to be expected, the healthy cohort is also the relatively wealthiest of the two health types. The difference is most pronounced after age 25, because from that age onward the instantaneous mortality rates start to deviate strongly (see Figure 1(b)).

\subsection{Pooling equilibrium}

If we reinstate assumption (A3), so that annuity firms are not able to observe an annuitant's health type, then the best such a firm can do is to set net return on annuities equal to a 
Table 2: Growth and adverse selection in the annuity market: quantitative effects

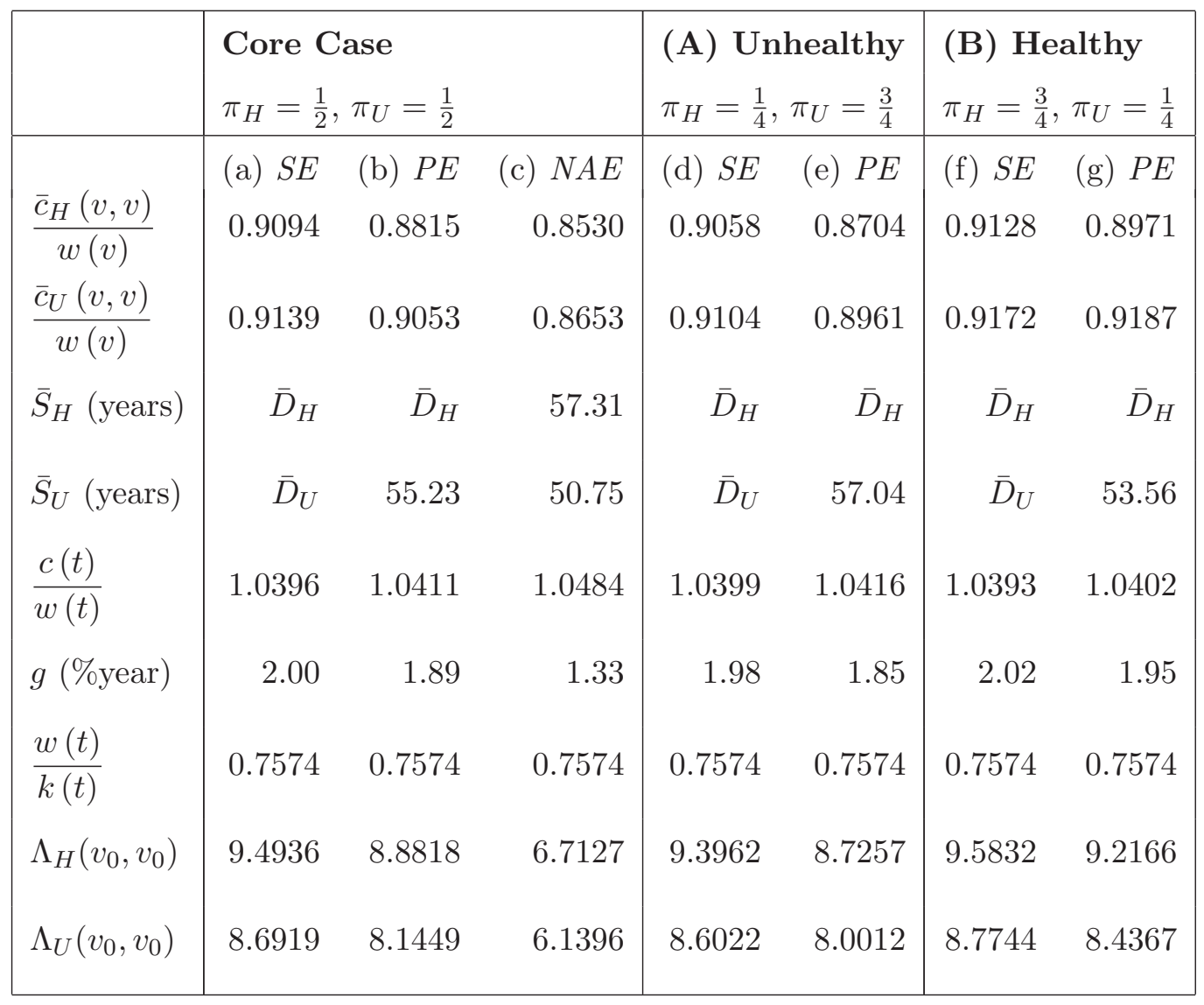

Notes. (a) $\pi_{j}$ is the population share of health type $j$ people, $\bar{S}_{j}$ is the age from which type $j$ faces a borrowing constraint. (b) SE is the separating equilibrium, PE the pooling equilibrium, and NAE stands for the equilibrium without annuities. (c) Maximum attainable ages are $\bar{D}_{H}=70.75$ and $\bar{D}_{U}=64.32$. (d) $\bar{c}_{j}(v, v) / w(v)$ is scaled newborn consumption by type $j, c(t)$ is per capita consumption, $w(t)$ is the wage rate, $k(t)$ is the capital stock per worker, and $g$ is the steady-state growth rate. See also notes in Table 1. 
(a) scaled individual consumption

$$
\frac{\bar{c}_{j}(v, v+u)}{w(v)}
$$

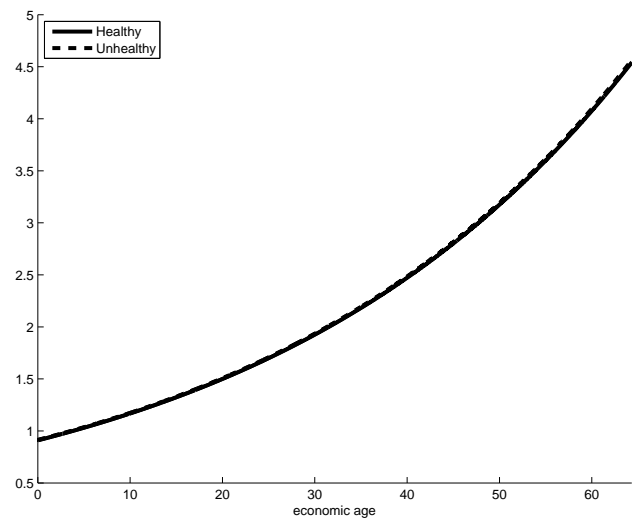

(c) "implied" relative pooling rate (U)

$$
\bar{p}(u)-\mu_{U}(u)
$$

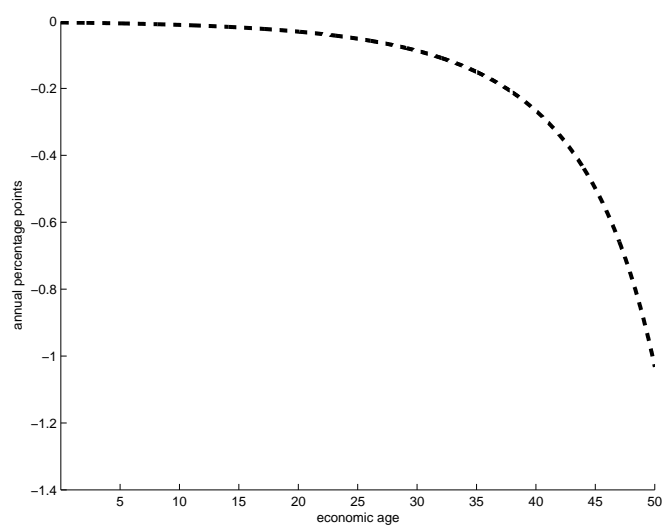

(b) scaled cohort assets

$$
\frac{a_{j}(v, v+u)}{w(v)}
$$

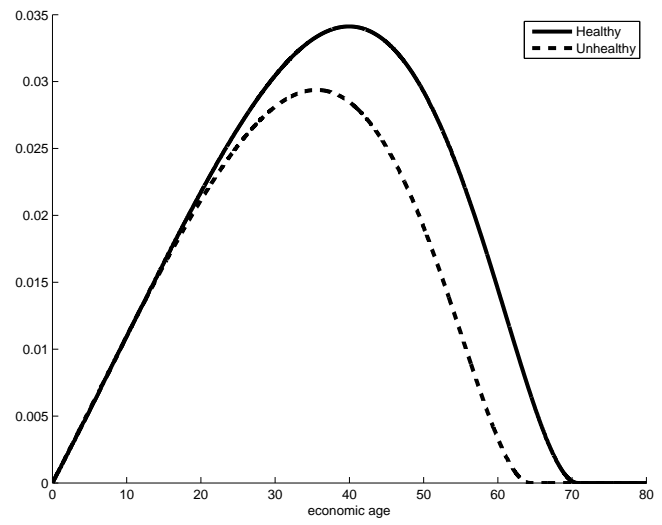

(d) "implied" relative pooling rate $(\mathrm{H})$

$$
\bar{p}(u)-\mu_{H}(u)
$$

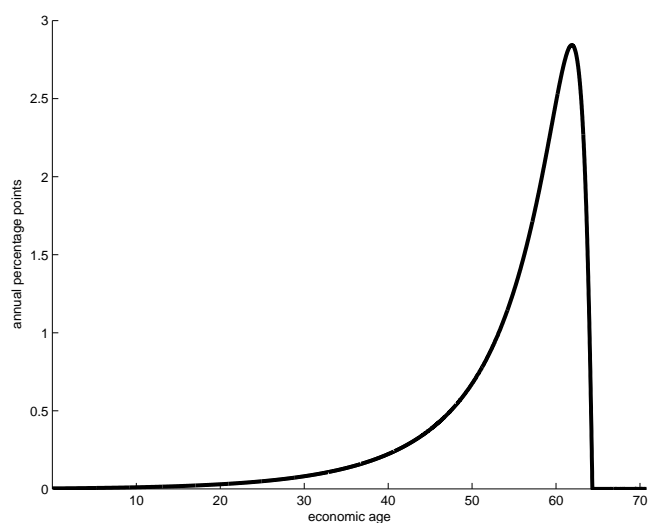

Figure 2: Separating equilibrium 
common, age-dependent, pooling rate $\bar{p}(u)$. This pooling rate takes the following form:

$$
\bar{p}(u)= \begin{cases}\frac{\mu_{H}(u) \cdot a_{H}(v, v+u)+\mu_{U}(u) \cdot a_{U}(v, v+u)}{a_{H}(v, v+u)+a_{U}(v, v+u)} & \text { for } 0<u \leq \bar{D}_{U} \\ \mu_{H}(u) & \text { for } \bar{D}_{U}<u<\bar{D}_{H}\end{cases}
$$

Annuity firms know that the unhealthy cannot live beyond age $\bar{D}_{U}$ so for $\bar{D}_{U}<u \leq \bar{D}_{H}$ no pooling is possible and $\bar{p}(u)$ coincides with the instantaneous mortality rate of the healthy individuals. For $0<u \leq \bar{D}_{U}$, however, both health types are alive and (potentially) active on the annuity market. The zero-profit condition for annuity firms furnishes the expression for the pooling rate in that case. It is the cohort-asset weighted sum of instantaneous mortality rates-see Sheshinski (2008, p. 71).

Using (3), (5), and (8) and ignoring borrowing constraints for the time being, we obtain the age profiles for consumption and assets for the two health types:

$$
\begin{aligned}
\frac{\dot{\bar{c}}_{j}(v, v+u)}{\overline{\bar{c}}_{j}(v, v+u)} & =r+\bar{p}(u)-\mu_{j}(u)-\rho, \\
\frac{\bar{a}_{j}(v, v+u)}{w(v)} \cdot e^{-r u-\bar{P}(u)} & =\int_{0}^{u} e^{-(r-g) s-\bar{P}(s)} d s-\frac{\bar{c}_{j}(v, v)}{w(v)} \int_{0}^{u} e^{-\rho s-M_{j}(s)} d s,
\end{aligned}
$$

where $\bar{P}(u) \equiv \int_{0}^{u} \bar{p}(s) d s$ for $0 \leq u \leq \bar{D}_{U}$ and $\bar{P}(u) \equiv \bar{P}\left(\bar{D}_{U}\right)+\int_{\bar{D}_{U}}^{u} \mu_{H}(s) d s$ for $\bar{D}_{U} \leq$ $u \leq \bar{D}_{H}$. Figure $2(\mathrm{c})$ provides a strong hint that this is not a complete description of the pooling equilibrium. To construct Figures 2(c)-(d), we use the cohort asset paths for the SE to compute the "implied" pooling rate $\bar{p}(u)$. Note that this is not an equilibrium rate because it is not consistent with the assumptions. Panel (d) shows that the healthy benefit a lot from pooling-their excess rate peaks at over 2.5 percentage points per annum around age 60 . In contrast, as panel (c) shows, the unhealthy lose out as a result of pooling. For the unhealthy the pooling rate becomes so low that they want to borrow at that rate. But in doing so, they would reveal their health status to annuity firms who would only be willing to lend them the funds at a punitively high rate equal to their mortality rate. But at that rate they would like to be savers, as the SE suggests. It follows that the best option for the unhealthy is to impose a binding borrowing constraint on themselves from age $\bar{S}_{U}<\bar{D}_{U}$ onward. We summarize as follows.

Proposition 2. Consider the pooling equilibrium (PE) in which annuity firms are unable to observe the health type of annuitants and assume that the growth-corrected interest rate exceeds the pure rate of time preference, $r-g>\rho$. Then: (i) healthy agents are net savers 
throughout life, i.e. $\bar{a}_{H}(v, v)=\bar{a}_{H}\left(v, v+\bar{D}_{H}\right)=0$ and $\bar{a}_{H}(v, v+u)>0$ for $0<u<\bar{D}_{H}$; (ii) unhealthy agents are net savers until age $\bar{S}_{U}<\bar{D}_{U}$ after which they adopt a self-imposed borrowing constraint to stay in the pooling equilibrium, i.e. $\bar{a}_{U}(v, v)=0, \bar{a}_{U}(v, v+u)>0$ for $0<u<\bar{S}_{U}$, and $\bar{a}_{U}(v, v+u)=0$ and $\bar{c}_{U}(v, v+u)=w(v+u)$ for $\bar{S}_{U} \leq u \leq \bar{D}_{U}$.

Proof. See Appendix B.

In the pooling equilibrium, we must redefine $\bar{P}(u) \equiv \bar{P}\left(\bar{S}_{U}\right)+\int_{\bar{S}_{U}}^{u} \mu_{H}(s) d s$ for $\bar{S}_{U} \leq u \leq$ $\bar{D}_{H}$. Equations (25)-(26) are valid for the healthy throughout life $\left(0 \leq u \leq \bar{D}_{H}\right)$, and for the unhealthy only until they hit the self-imposed borrowing constraint $\left(0 \leq u \leq \bar{S}_{U}\right)$. Beyond age $\bar{S}_{H}$ the unhealthy simply consume their wage income.

The key equations of the pooling general equilibrium model are collected in Table 3. Equations (T3.1)-(T3.2) are obtained by using (8) in (4) and noting that the integrals only run up to age $\bar{S}_{U}$ for the unhealthy. Equation (T3.3) is the smooth-connection condition: consumption at age $\bar{S}_{U}$ must connect without discontinuity with the level implied by the solved Euler equation under pooling. ${ }^{6}$ Equations (T3.4)-(T3.6) are the cohort asset paths under pooling, taking account of the self-imposed borrowing constraint for the unhealthy. Equation (T3.7) states the expression for the pooling rate. Equation (T3.8) is obtained from (9) by setting $\bar{S}_{H}=\bar{D}_{H}, P_{j}(s)=\bar{P}(s)$, and noting the definition of $c(t)$. The growth expression, equation (T3.9), again follows readily from (11) because $a(t)=k(t)$ and $\Xi(t)=0$. In the $\mathrm{PE}$, redistribution between health groups does take place but it washes out in the aggregate as the annuity firms break even. Hence, the growth equation is the same as in the SE. Finally, equation (T3.10) is the same as before.

Using the parameter values discussed above, we can compute the pooling equilibrium using an iterative solution algorithm. ${ }^{7}$ The results are reported in column (b) of Table 2 for the core case. Relative to the SE, newborn consumption for both health types is slightly lower in the PE. Similarly, the economic growth rate is somewhat less in the $\mathrm{PE}-1.89$ percent per annum

\footnotetext{
${ }^{6}$ Solving equation (25) for the unhealthy gives (for $\left.0 \leq u \leq \bar{S}_{U}\right): \bar{c}_{U}(v, v+u)=\bar{c}_{U}(v, v) e^{(r-\rho) u-M_{U}(u)+\bar{P}(u)}$. For $\bar{S}_{U} \leq u \leq \bar{D}_{U}$ we have: $\bar{c}_{U}(v, v+u)=w(v) e^{g u}$. For $u=\bar{S}_{U}$ these two expressions must coincide. This furnishes equation (T3.3) in Table 3.

${ }^{7}$ We drop equation (T3.3) and perform a grid search over $S_{U}$ which solves the remaining general equilibrium system. To get the iterations started we use the pooling rate "implied by" the SE. See Figures 2(c)-(d). The iterations are stopped once a value for $S_{U}$ is found which solves (T3.3).
} 
Table 3: Balanced growth in the pooling equilibrium

(a) Microeconomic relationships:

$$
\begin{aligned}
\frac{\bar{c}_{H}(v, v)}{w(v)}= & \frac{\int_{0}^{\bar{D}_{H}} e^{-(r-g) s-\bar{P}(s)} d s}{\int_{0}^{\bar{D}_{H}} e^{-\rho s-M_{H}(s)} d s} \\
\frac{\bar{c}_{U}(v, v)}{w(v)}= & \frac{\int_{0}^{\bar{S}_{U}} e^{-(r-g) s-\bar{P}(s)} d s}{\int_{0}^{\bar{S}_{U}} e^{-\rho s-M_{U}(s)} d s} \\
\frac{\bar{c}_{U}(v, v)}{w(v)}= & e^{-(r-g-\rho) \bar{S}_{U}+M_{U}\left(\bar{S}_{U}\right)-\bar{P}\left(\bar{S}_{U}\right)} \\
\frac{a_{H}(v, v+u)}{w(v)}= & \beta_{H} \pi_{H} e^{(r-n) u-M_{H}(u)+\bar{P}(u)} \cdot\left[\int_{0}^{u} e^{-(r-g) s-\bar{P}(s)} d s\right. \\
\frac{a_{U}(v, v+u)}{w(v)}= & \left.-\frac{\bar{c}_{H}(v, v)}{w(v)} \int_{0}^{u} e^{-\rho s-M_{H}(s)} d s\right], \quad\left(0 \leq u \leq \bar{D}_{H}\right) \\
\frac{a_{U}(r-n) u-M_{U}(u)+\bar{P}(u)}{(v, v+u)} & \left.-\frac{\bar{c}_{U}(v, v)}{w(v)} \int_{0}^{u} e^{-\rho s-M_{U}(s)} d s\right], \quad\left(0 \leq u \leq \bar{S}_{U}\right) \\
w(v) & 0, \quad\left(\bar{S}_{U} \leq u \leq \bar{D}_{U}\right) \\
\bar{p}(u)= & \frac{\mu_{H}(u) \cdot a_{H}(v, v+u)+\mu_{U}(u) \cdot a_{U}(v, v+u)}{a_{H}(v, v+u)+a_{U}(v, v+u)} d s
\end{aligned}
$$

(b) Macroeconomic relationships:

$$
\begin{aligned}
\frac{c(t)}{w(t)} & =\beta_{H} \pi_{H} \cdot \frac{\bar{c}_{H}(v, v)}{w(v)} \cdot \int_{0}^{\bar{D}_{H}} e^{(r-n-g-\rho) s-2 M_{H}(s)+\bar{P}(s)} d s \\
+ & \beta_{U} \pi_{U} \cdot\left[\frac{\bar{c}_{U}(v, v)}{w(v)} \int_{0}^{\bar{S}_{U}} e^{(r-n-g-\rho) s-2 M_{U}(s)+\bar{P}(s)} d s+\int_{\bar{S}_{U}}^{\bar{D}_{U}} e^{-n s-M_{U}(s)} d s\right] \\
g & \equiv \frac{\dot{k}(t)}{k(t)}=r-n+\left[1-\frac{c(t)}{w(t)}\right] \cdot \frac{w(t)}{k(t)} \\
\frac{w(t)}{k(t)} & =(1-\varepsilon) \Omega_{0}
\end{aligned}
$$

Notes. (a) Endogenous are $\bar{c}_{j}(v, v) / w(v), a_{j}(v, v+u) / w(v), \bar{p}(u), \bar{S}_{U}, g, w(t) / k(t)$, and $c(t) / w(t)$. (b) $\bar{P}(s)$ is the cumulative pooling rate at age $s$, and $u \equiv t-v$. See also notes in Table 1 . 
instead of 2 percent. Interestingly, the unhealthy encounter the borrowing constraint fairly early on in life, namely at economic age 55.23 which is 9.09 years less than their maximum attainable age. In a number of papers, Leung $(1994,2007)$ has found a related result. He uses a partial equilibrium model in which annuities are absent altogether and there is only one health type and shows that individuals expect to run out of assets if they live long enough. In contrast, in our approach, annuitization opportunities vanish endogenously for the unhealthy but remain in place for the healthy.

Figure 3 visualizes the key life-cycle features of the PE for the two health groups. Panel (a) shows that scaled consumption for the unhealthy reaches a local peak just before encountering the borrowing constraint at $\bar{S}_{U}$. This is because the pooling rate is rather low (due to the predominance of the healthy in the annuity market), and the mortality rate of the healthy starts to rise. In terms of (25), consumption falls for a while because the gross annuity rate, $r+\bar{p}(u)$, falls short of the "effective impatience rate" due to time preference and mortality, $\rho+\mu_{U}(u)$, for $u$ near $\bar{S}_{H}$. At $u=\bar{S}_{U}$, the surviving unhealthy reach the Keynesian part of their consumption profile and simply consume their wage income.

Comparing the asset paths for the SE and PE cases in, respectively, Figures 2(b) and 3(b), we observe that the healthy save much more and the unhealthy save much less in the PE than in the SE. This is in part because the relative pooling rate, $\bar{p}_{j}(u)-\mu_{j}(u)$, is positive for the healthy and is negative for the unhealthy. This is visualized in panels (c)-(d) in Figure 3. In a sense, the healthy benefit from the presence of the unhealthy in the annuity market and are thus able to obtain an annuity rate of interest on their assets that is more than actuarially fair.

As a robustness check we consider two alternative cases in Table 2 (panels (d)-(g)) and in Figure 4. In the case labeled "Unhealthy" in Table 2 we keep all but one of the model parameters unchanged but assume that the proportion of unhealthy people is $\frac{3}{4}$ rather than $\frac{1}{2}$. A number of features stand out. First, comparing panels (d) and (a) (or indeed, (e) and (b)) we observe that the effects on individual and aggregate consumption as well as growth are rather small. Second, for the PE case the unhealthy encounter the borrowing constraint later in life (at $\bar{S}_{U}=57.04$ ) in an unhealthy economy than under the core case (for which case $\bar{S}_{U}=55.23$ ). Intuitively, as Figure 4(b) shows, though modest savers at the individual level, the cohort asset share of the unhealthy is dominant for a large age domain. This implies 
(a) scaled individual consumption

$$
\frac{\bar{c}_{j}(v, v+u)}{w(v)}
$$

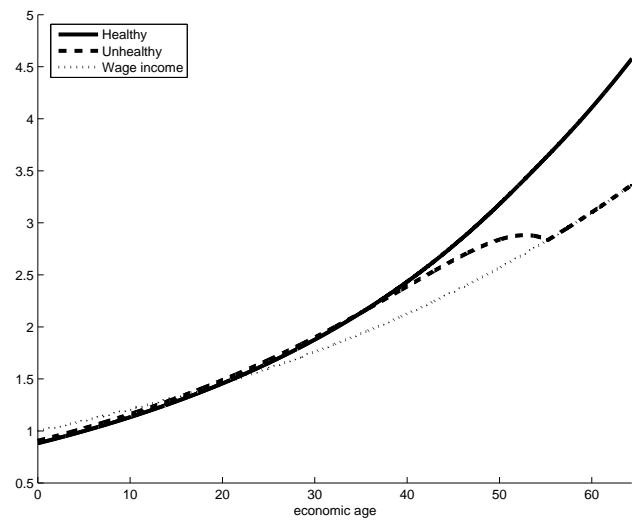

(c) relative pooling rate $(\mathrm{U})$

$$
\bar{p}(u)-\mu_{U}(u)
$$

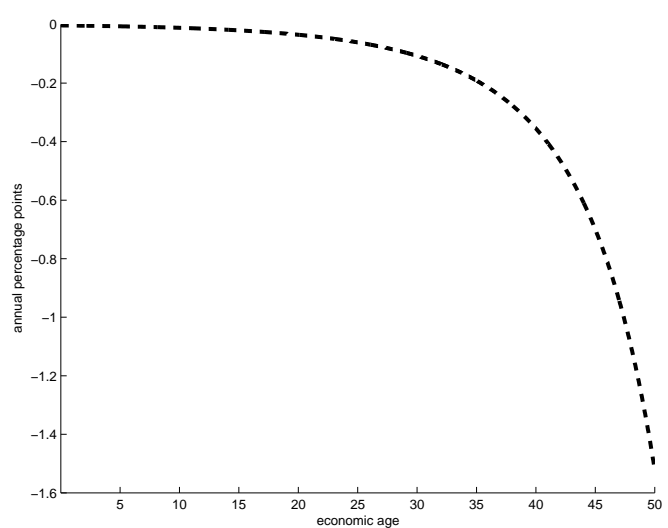

(b) scaled cohort assets

$$
\frac{a_{j}(v, v+u)}{w(v)}
$$

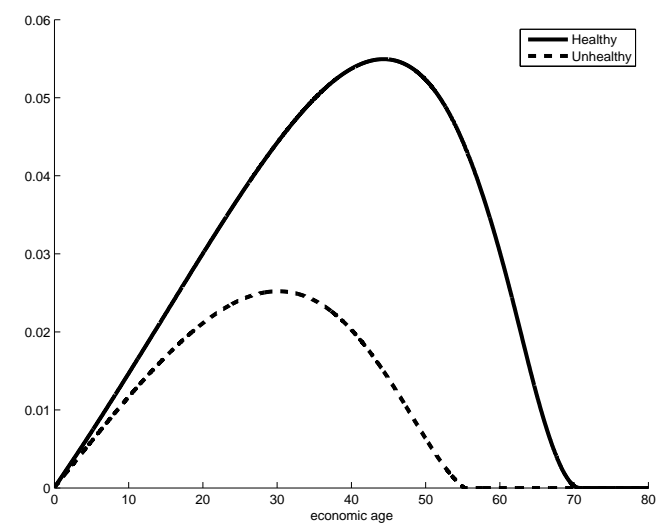

(d) relative pooling rate $(\mathrm{H})$

$$
\bar{p}(u)-\mu_{H}(u)
$$

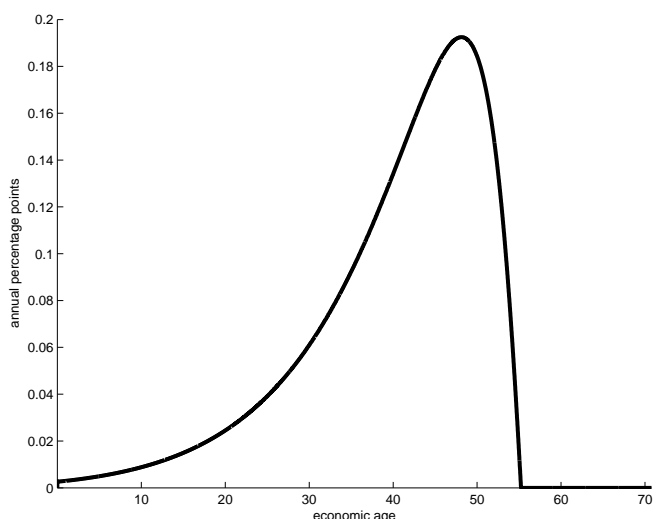

Figure 3: Pooling equilibrium 
(A) Unhealthy population: $\pi_{H}=1-\pi_{U}=\frac{1}{4}$

(a) relative pooling rate $(\mathrm{H})$

$$
\bar{p}(u)-\mu_{H}(u)
$$

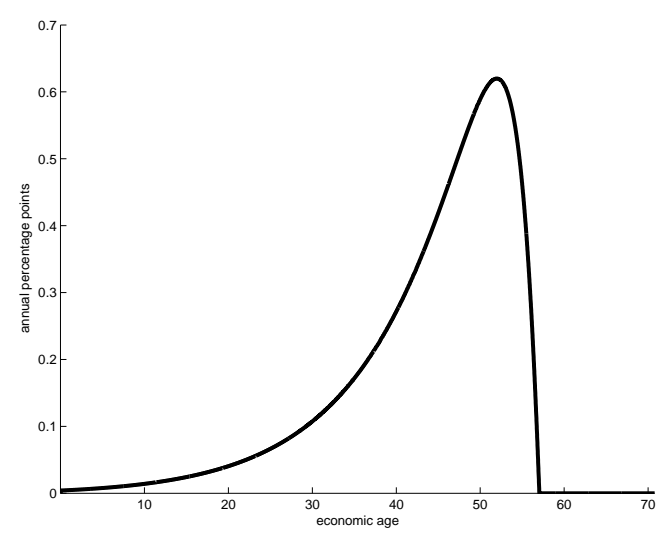

(B) Healthy population: $\pi_{H}=1-\pi_{U}=\frac{3}{4}$

(c) relative pooling rate $(\mathrm{H})$

$$
\bar{p}(u)-\mu_{H}(u)
$$

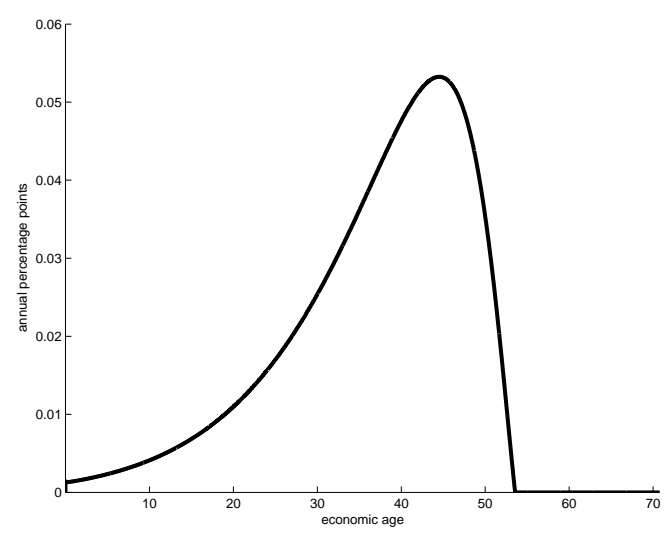

(b) scaled cohort assets

$$
\frac{a_{j}(v, v+u)}{w(v)}
$$

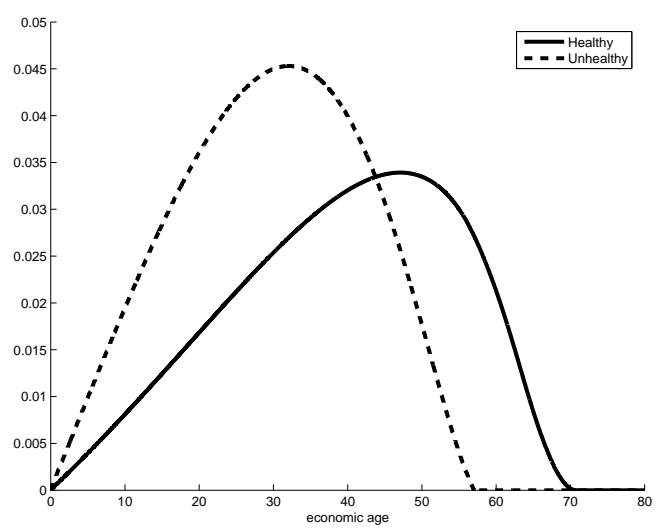

(d) scaled cohort assets

$$
\frac{a_{j}(v, v+u)}{w(v)}
$$

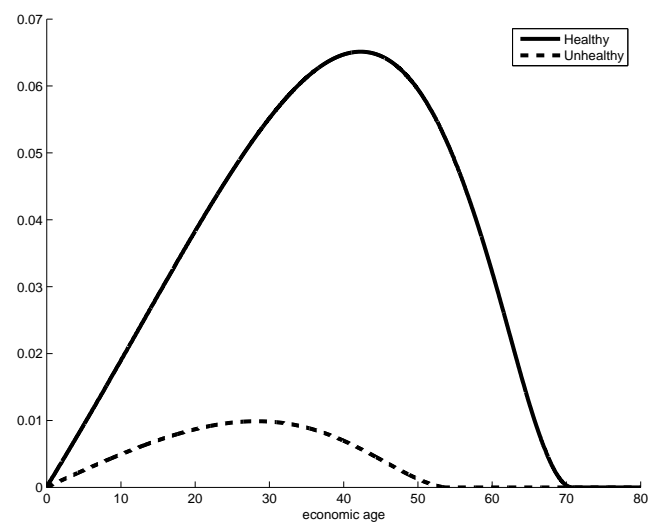

Figure 4: Pooling equilibrium with unequal health group sizes 
that the pooling rate remains relatively close to the mortality rate of the unhealthy which postpones the borrowing age somewhat - compare Figures 3(d) and 4(a). Third, a comparison between panels (d) and (e) of Table 2 yields virtually identical conclusions as were obtained for the core case.

Finally, in panels (f)-(e) of Table 2 and Figures 4(c)-(d) we characterize the "Healthy" case, in which the unhealthy are a minority $\left(\pi_{H}=\frac{3}{4}\right.$ and $\left.\pi_{U}=\frac{1}{4}\right)$. The conclusions from this case are the mirror images of those from the "Unhealthy" case.

\subsection{Welfare analysis}

In the previous subsection we have shown that the growth effects of "pooling versus separation" are rather small even though the difference in mortality risks faced by healthy and unhealthy individuals is rather large especially at older ages (see Figure 1(b)). But economic growth is not the only relevant indicator. A key question is, to what extent does it matter to individuals whether or not the annuity markets are perfect (SE) or imperfect (PE)?

To address this question, the last two rows of Table 2 report the lifetime utility scores for newborns (of both health type) at some base year $v_{0}$. We normalize the wage rate for that generation to unity, $w\left(v_{0}\right)=1$. As Table 2 reveals, welfare is higher under the SE than under the PE, i.e. $\Lambda_{j}^{S E}\left(v_{0}, v_{0}\right)>\Lambda_{j}^{P E}\left(v_{0}, v_{0}\right)$ for $j \in\{H, U\}$. In order to obtain some feel for the significance of these differences, we compute lost growth years under annuity market equilibrium $i$ relative to the separating equilibrium as follows:

$$
L G Y_{j}^{i}=\frac{1}{g^{i}} \cdot \frac{\Lambda_{j}^{S E}\left(v_{0}, v_{0}\right)-\Lambda_{j}^{i}\left(v_{0}, v_{0}\right)}{\int_{0}^{\bar{D}_{j}} e^{-\rho s-M_{j}(s)} d s} .
$$

Intuitively, $L G Y_{j}^{i}$ is equal to $v_{1}-v_{0}$ such that $\Lambda_{j}^{S E}\left(v_{0}, v_{0}\right)=\Lambda_{j}^{i}\left(v_{1}, v_{1}\right)$. How far into the future must a newborn arrive under annuity market $i$ in order to be equally well off as a baseyear newborn in the SE? Since wage growth explains why newborn lifetime utility increases over time, the macroeconomic growth rate under annuity market $i$ features in (27).

For $i=P E$ the comparison is between the PE and the SE and we find that $L G Y_{H}^{P E}=$ 1.3478 years and $L G Y_{U}^{P E}=1.2439$ years. By all accounts the annuity market imperfection due to pooling is rather small in welfare terms. At birth, the unhealthy have a life expectancy ${ }^{8}$ of 56.62 years and for them the lost growth years amount to about 14.9 months. For the

\footnotetext{
${ }^{8}$ Life expectancy at birth for type $j$ individuals is equal to $\int_{0}^{\bar{D}_{j}} e^{-M_{j}(s)} d s$.
} 
(a) scaled individual consumption

$$
\frac{\bar{c}_{j}(v, v+u)}{w(v)}
$$

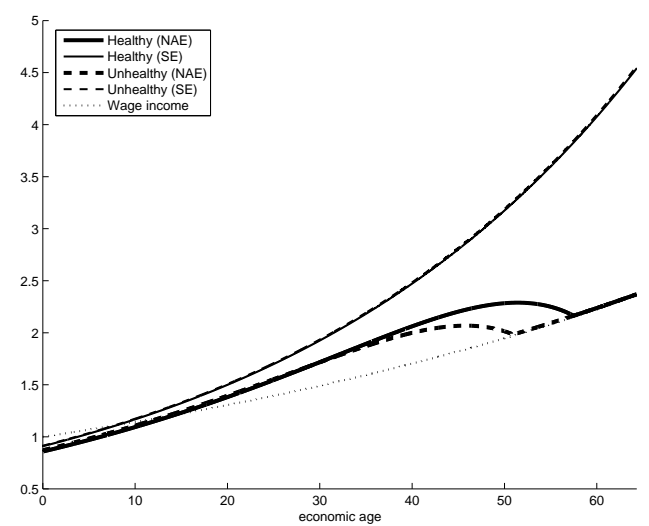

(b) scaled individual assets

$$
\frac{\bar{a}_{j}(v, v+u)}{w(v)}
$$

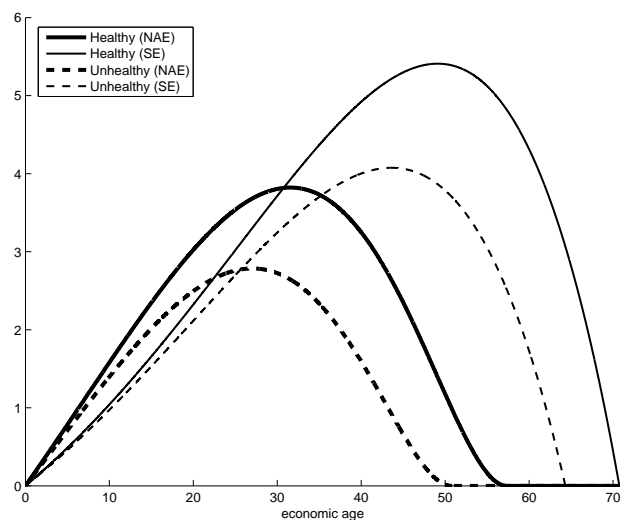

Figure 5: Equilibrium with missing annuity market

healthy the results are 16.2 months of lost growth on an expected lifetime at birth of 51.48 years. These are not of an order of magnitude that should worry the policy maker.

At first sight it might appear as though the above results imply that the pooling equilibrium does not exist. Both the unhealthy agents and the healthy agents as a group are better of by truthfully signaling their health status to the annuity firms. As a separating equilibrium gives them higher utility, this announcement would be credible. However, each healthy agent as an individual has an incentive to deviate from the optimal group strategy. Once the separating equilibrium is realized, posing as an unhealthy (low risk) agent and receiving the higher annuity premium is optimal given that the other agents are honest in their health claim. Indeed, a cheating healthy individual would attain a welfare level of $\Lambda_{H}^{S E, C}\left(v_{0}, v_{0}\right)=10.4983$ which far exceeds the truth-telling value of $\Lambda_{H}^{S E}\left(v_{0}, v_{0}\right)=9.4936$. There thus exists a freerider problem: as each healthy agent has an incentive to cheat and they cannot coordinate their actions, the pooling equilibrium will be the inevitable, yet suboptimal, outcome.

The crucial thing to note is that in the $\mathrm{PE}$, individuals are able to insure themselves against longevity risk. Even with imperfect insurance opportunities, the welfare gains due to annuitization are huge. To illustrate this phenomenon, we compute the general equilibrium outcome for the core case when no annuities are available at all. We label this no-annuities 
equilibrium NAE, report it in Table 2(c), and visualize it in Figure 5. Panel (c) of Table 2 reveals that in the NAE the growth rate is only 1.33 percent per annum and that both health groups encounter binding borrowing constraints rather early on in life. Not surprisingly, the lost growth year indicators are very large. For the healthy we find $L G Y_{H}^{N A E}=8.6764$ years, whilst for the unhealthy we obtain $L G Y_{U}^{N A E}=8.2202$ years.

\section{Conclusions}

We have constructed a consistent general equilibrium model featuring endogenous economic growth and overlapping generations of heterogeneous agents distinguished by health status. Since an individual's health status and annuity purchases are private information, competitive annuity firms offer linear contracts so that a risk pooling equilibrium emerges. In this equilibrium the healthy (high-risk) individuals benefit from the market presence of unhealthy (low-risk) annuitants. The model gives a partial explanation for the annuity puzzle. At high ages, low-risk individuals cease to purchase annuities and impose a borrowing constraint on themselves. Interestingly, the growth and welfare effects of the annuity market imperfection due to adverse selection are rather small. The annuity puzzle may be quantitatively unimportant after all.

In future works we hope to pursue the following extensions. First, we wish to endogenize the labour supply decision in order to investigate the retirement effects of annuity market imperfections. In that context we will also introduce social annuity schemes such as a PAYG pension system. Second, we wish to model the optimal schooling decision by individuals in an adverse selection setting and study the effects on aggregate human capital formation and macroeconomic growth. Finally, we want to extend the model to include multiple health types and study the emergence of joint pooling equilibria for annuities and life-insurance. 


\section{Appendix A: Proof of Proposition 1}

In a separating equilibrium we have $M_{j}(u)=P_{j}(u)$ for all $0 \leq u \leq \bar{D}_{U}$ as $p_{j}(u)=\mu_{j}(u)$ for all $0 \leq u \leq \bar{D}_{j}$. Since $\rho<r-g$ we find:

$$
\frac{\bar{c}_{j}(v, v)}{w(v)}=\frac{\int_{0}^{\bar{D}_{j}} e^{-(r-g) u-M_{j}(u)} d u}{\int_{0}^{\bar{D}_{j}} e^{-\rho u-M_{j}(u)} d u}<1 .
$$

Let $u \in\left[0, \bar{D}_{j}\right]$ be the age of the consumer. Then we can write:

$$
\frac{\bar{a}_{j}(v, v+u)}{w(v)} e^{-r u-M_{j}(u)}=\Gamma_{j}(u)
$$

where $\Gamma_{j}:\left[0, \bar{D}_{j}\right] \rightarrow \mathbb{R}$ is defined by:

$$
\Gamma_{j}(u)=\int_{0}^{u} e^{-(r-g) s-M_{j}(s)} d s-\frac{\bar{c}_{j}(v, v)}{w(v)} \int_{0}^{u} e^{-\rho s-M_{j}(s)} d s .
$$

As $\Gamma_{j}$ is a continuous function defined on a closed and bounded interval $\left[0, \bar{D}_{j}\right]$, we know that $\Gamma_{j}$ has a global maximum and a global minimum on its domain. Candidates for these extreme points are the boundaries of the domain and the interior critical points. For the boundary points we find $\Gamma(0)=\Gamma\left(\bar{D}_{j}\right)=0$ as $\bar{a}_{j}(v, v)=\bar{a}_{j}\left(v, v+\bar{D}_{j}\right)$ by the initial condition and the property of nonsaturation.

Using Leibnitz' rule, we find that the first order derivative of $\Gamma$ is given by:

$$
\begin{aligned}
\Gamma_{j}^{\prime}(u) & =e^{-(r-g) u-M_{j}(u)}-\frac{\bar{c}_{j}(v, v)}{w(v)} e^{-\rho u-M_{j}(u)} \\
& =e^{-M_{j}(u)}\left[e^{-(r-g) u}-\frac{\bar{c}_{j}(v, v)}{w(v)} e^{-\rho u}\right] .
\end{aligned}
$$

The unique interior root of this equation is:

$$
u^{*} \equiv-\frac{1}{r-g-\rho} \cdot \ln \left(\frac{\bar{c}_{j}(v, v)}{w(v)}\right),
$$

where $u^{*}>0$ as $\bar{c}_{j}(v, v) / w(v)<1$ and $r-g>\rho$ by assumption. We find that $\Gamma_{j}^{\prime}(u)>0$ for $0 \leq u<u^{*}$ and $\Gamma_{j}^{\prime}(u)<0$ for $u^{*}<u<\bar{D}_{j}$. We conclude that $\Gamma_{j}$ has a global maximum at $u^{*}$ and a global minimum at 0 and $\bar{D}_{j}$. As this global minimum equals zero, we find $\bar{a}_{j}(v, v+u)>0$ for all $u \in\left(0, \bar{D}_{j}\right)$. 


\section{Appendix B: Proof of Proposition 2}

The pooling equilibrium only exists if the health types cannot be distinguished. The case with only borrowers $\left(\bar{a}_{H}(v, v+u) \leq 0\right.$ and $\left.\bar{a}_{U}(v, v+u) \leq 0\right)$ is inconsistent with a macroeconomic equilibrium in a closed economy. This leaves us with the alternative case, with some savers, i.e. $\bar{a}_{H}(v, v+u) \geq 0$ and $\bar{a}_{U}(v, v+u) \geq 0$ with strict equality for some type and/or $u$. The feasible pooling rate is defined as:

$$
\bar{p}(u)=\left\{\begin{array}{ll}
\frac{\mu_{H}(u) \cdot a_{H}(v, v+u)+\mu_{U}(u) \cdot a_{U}(v, v+u)}{a_{H}(v, v+u)+a_{U}(v, v+u)} & \text { for } 0<u \leq \bar{D}_{U} \\
\mu_{H}(u) & \text { for } \bar{D}_{U}<u<\bar{D}_{H}
\end{array} .\right.
$$

It follows that:

$$
\begin{aligned}
\mu_{H}(s) & \leq \bar{p}(s) \leq \mu_{U}(s), \quad \text { for } 0<s \leq \bar{D}_{U}, \\
M_{H}(u) & \leq \bar{P}(u) \leq M_{U}(u), \quad \text { for } 0<u \leq \bar{D}_{U}, \\
\bar{P}(u) & =\bar{P}\left(\bar{D}_{U}\right)+\int_{\bar{D}_{U}}^{u} \mu_{H}(s) d s, \quad \text { for } \bar{D}_{U}<u \leq \bar{D}_{H} .
\end{aligned}
$$

For type $H$ individuals we easily find:

$$
\left(\frac{\bar{c}_{H}(v, v)}{w(v)}\right)^{P E}=\frac{\int_{0}^{\bar{D}_{H}} e^{-(r-g) s-\bar{P}(s)} d s}{\int_{0}^{\bar{D}_{H}} e^{-\rho s-M_{H}(s)} d s}=\frac{\int_{0}^{\bar{D}_{H}} f(s) \cdot e^{-(r-g) s-M_{H}(s)} d s}{\int_{0}^{\bar{D}_{H}} e^{-\rho s-M_{H}(s)} d s},
$$

where the superscript " $P E$ " stands for pooling equilibrium and $f(s)$ is defined as follows:

$$
\begin{aligned}
f(s) & \equiv e^{M_{H}(s)-\bar{P}(s)} \leq 1 \quad \text { for } 0<s \leq \bar{D}_{H}, \\
f(0) & =1 \\
f^{\prime}(s) & =\left[\mu_{H}(s)-\bar{p}(s)\right] \cdot f(s) \leq 0 .
\end{aligned}
$$

It follows immediately that:

$$
\begin{aligned}
& \left(\frac{\bar{c}_{H}(v, v)}{w(v)}\right)^{P E} \leq\left(\frac{\bar{c}_{H}(v, v)}{w(v)}\right)^{S E}<1 \\
& \left(\frac{\dot{\bar{a}}_{H}(v, v)}{w(v)}\right)^{P E}=1-\left(\frac{\bar{c}_{H}(v, v)}{w(v)}\right)^{P E} \geq\left(\frac{\dot{\bar{a}}_{H}(v, v)}{w(v)}\right)^{S E}=1-\left(\frac{\bar{c}_{H}(v, v)}{w(v)}\right)^{S E}>0,
\end{aligned}
$$

the superscript "SE" stands for the separating equilibrium. The $H$-types start saving more vigorously at the start of life. The assets of $\mathrm{H}$-individuals satisfy:

$$
\frac{\bar{a}_{H}(v, t)}{w(v)} \cdot e^{-r u-\bar{P}(u)}=\left(\frac{\bar{c}_{H}(v, v)}{w(v)}\right)^{P E} \cdot \int_{u}^{\bar{D}_{U}} e^{-\rho s-M_{H}(s)} d s-\int_{u}^{\bar{D}_{U}} f(s) e^{-(r-g) s-M_{H}(s)} d s \equiv \Xi_{H}(u),
$$


with $\Xi_{H}(0)=\Xi_{H}\left(\bar{D}_{H}\right)=0$. Taking the first derivative we obtain:

$$
\Xi_{H}^{\prime}(u)=e^{-M_{H}(u)} \cdot\left[f(u) e^{-(r-g) u}-\left(\frac{\bar{c}_{H}(v, v)}{w(v)}\right)^{P E} e^{-\rho u}\right] .
$$

Hence, the stationary point, $u_{H}^{*}$, is such that:

$$
\left(\frac{\bar{c}_{H}(v, v)}{w(v)}\right)^{P E} \cdot e^{(r-g-\rho) u_{H}^{*}}=f\left(u_{H}^{*}\right) .
$$

The second derivative (evaluated at $u_{H}^{*}$ ) is:

$$
\Xi_{H}^{\prime \prime}\left(u_{H}^{*}\right)=-e^{-M_{H}\left(u_{H}^{*}\right)-(r-g) u_{H}^{*}} \cdot\left[(r-g-\rho) f\left(u_{H}^{*}\right)-f^{\prime}\left(u_{H}^{*}\right)\right]<0,
$$

so we have a unique interior maximum, and $\Xi_{H}(u)>0$ for $0<u<\bar{D}_{H}$. We conclude that:

$$
\frac{\bar{a}_{H}(v, v)}{w(v)}=\frac{\bar{a}_{H}\left(v, v+\bar{D}_{H}\right)}{w(v)}=0, \quad \frac{\bar{a}_{H}(v, v+u)}{w(v)}>0 \quad \text { for } 0<u \leq \bar{D}_{H} .
$$

Except at the start and the end of life, the H-types keep positive assets throughout. It follows that we can establish the strict inequalities $\bar{p}(s)<\mu_{U}(s)$ and $\bar{P}(u)<M_{U}(u)$ for $0<s, u \leq \bar{D}_{U}$.

For type $U$ individuals we find:

$$
\left(\frac{\bar{c}_{U}(v, v)}{w(v)}\right)^{P E}=\frac{\int_{0}^{\bar{D}_{U}} e^{-(r-g) s-\bar{P}(s)} d s}{\int_{0}^{\bar{D}_{U}} e^{-\rho s-M_{U}(s)} d s}=\frac{\int_{0}^{\bar{D}_{U}} h(s) \cdot e^{-(r-g) s-M_{U}(s)} d s}{\int_{0}^{\bar{D}_{U}} e^{-\rho s-M_{U}(s)} d s},
$$

where $h(s)$ is given by:

$$
\begin{aligned}
h(s) & \equiv e^{M_{U}(s)-\bar{P}(s)}>1 \quad \text { for } 0<s \leq \bar{D}_{U}, \\
h(0) & =1 \\
h^{\prime}(s) & =\left[\mu_{U}(s)-\bar{p}(s)\right] \cdot h(s)>0 .
\end{aligned}
$$

It follows that type $U$ individuals consume more at birth in the pooling equilibrium than in the separating equilibrium:

$$
\left(\frac{\bar{c}_{U}(v, v)}{w(v)}\right)^{P E}>\left(\frac{\bar{c}_{U}(v, v)}{w(v)}\right)^{S E}
$$

We can rule out that the left-hand side is greater than one, because then the U-types would start to borrow immediately (which is inconsistent with the $\mathrm{PE}$ ). The assets of type $U$ individuals satisfy:

$$
\frac{\bar{a}_{U}(v, t)}{w(v)} \cdot e^{-r u-\bar{P}(u)}=\left(\frac{\bar{c}_{U}(v, v)}{w(v)}\right)^{P E} \int_{u}^{\bar{D}_{U}} e^{-\rho s-M_{U}(s)} d s-\int_{u}^{\bar{D}_{U}} h(s) e^{-(r-g) s-M_{U}(s)} d s \equiv \Xi_{U}(u),
$$


with $\Xi_{U}(0)=\Xi_{U}\left(\bar{D}_{U}\right)=0$. Taking the first derivative we obtain:

$$
\Xi_{U}^{\prime}(u)=e^{-M_{U}(u)} \cdot\left[h(u) e^{-(r-g) u}-\left(\frac{\bar{c}_{U}(v, v)}{w(v)}\right)^{P E} e^{-\rho u}\right] .
$$

Hence, a stationary point, $u_{U}^{*}$ is such that:

$$
\left(\frac{\bar{c}_{U}(v, v)}{w(v)}\right)^{P E} \cdot e^{(r-g-\rho) u_{U}^{*}}=h\left(u_{U}^{*}\right) .
$$

Note that both sides are increasing in $u_{U}^{*}$ opening up the possibility of multiple equilibria. The second derivative (evaluated at $u_{U}^{*}$ ) is:

$$
\Xi_{U}^{\prime \prime}\left(u_{U}^{*}\right)=-h\left(u_{U}^{*}\right) e^{-M_{U}\left(u_{U}^{*}\right)-(r-g) u_{U}^{*}} \cdot\left[(r-g-\rho)-\left[\mu_{U}\left(u_{U}^{*}\right)-\bar{p}\left(u_{U}^{*}\right)\right]\right] \lesseqgtr 0,
$$

where we have used the fact that $h^{\prime}\left(u_{U}^{*}\right)=\left[\mu_{U}\left(u_{U}^{*}\right)-\bar{p}\left(u_{U}^{*}\right)\right] \cdot h\left(u_{U}^{*}\right)$. There are two interior optima. Since $r-g>\rho$ and $\mu_{U}(u)-\bar{p}(u) \approx 0$ for low $u$, the first stationary point $u_{U 1}^{*}$ is a maximum $\left(\Xi_{U}^{\prime \prime}\left(u_{U 1}^{*}\right)<0\right)$. But $\lim _{u \rightarrow \bar{D}_{U}}\left[\mu_{U}(u)-\bar{p}(u)\right] \rightarrow \infty$ so the second optimum $u_{U 2}^{*}$ is a minimum $\left(\Xi_{U}^{\prime \prime}\left(u_{U 2}^{*}\right)>0\right)$. Since both sides of (B.2) are convex exponential functions, there can only be two stationary points so the second optimum is associated with negative assets. We conclude that:

$\frac{\bar{a}_{U}(v, v+u)}{w(v)}=0 \quad\left(\right.$ for $u=0$ and $\left.\bar{S}_{U} \leq u \leq \bar{D}_{U}\right), \quad \frac{\bar{a}_{U}(v, v+u)}{w(v)}>0 \quad\left(\right.$ for $\left.0<u<\bar{S}_{U}\right)$.

Type $U$ individuals deplete their assets before reaching the maximum attainable age. 


\section{References}

Abel, A. B. (1986). Capital accumulation and uncertain lifetimes with adverse selection. Econometrica, 54:1079-1098.

Davidoff, T., Brown, J. R., and Diamond, P. A. (2005). Annuities and individual welfare. American Economic Review, 95:1573-1590.

Eichenbaum, M. S. and Peled, D. (1987). Capital accumulation and annuities in an adverse selection economy. Journal of Political Economy, 95(2):334-54.

Finkelstein, A. and Poterba, J. (2002). Selection effects in the United Kingdom individual annuities market. Economic Journal, 112(476):28-50.

Finkelstein, A. and Poterba, J. (2004). Adverse selection in insurance markets: Policyholder evidence from the U.K. annuity market. Journal of Political Economy, 112(1):183-208.

Finkelstein, A., Poterba, J., and Rothschild, C. (2009). Redistribution by insurance market regulation: Analyzing a ban on gender-based retirement annuities. Journal of Financial Economics, 91:38-58.

Friedman, B. M. and Warshawsky, M. J. (1988). Annuity prices and saving behavior in the United States. In Bodie, Z., Shoven, J. B., and Wise, D. A., editors, Pensions in the U.S Economy, pages 53-77. University of Chicago Press, Chicago.

Friedman, B. M. and Warshawsky, M. J. (1990). The costs of annuities: Implications for saving behavior and bequests. Quarterly Journal of Economics, 105:135-154.

Heijdra, B. J. and Mierau, J. O. (2009). Annuity market imperfection, retirement and economic growth. Working Paper 2717, CESifo, München.

Heijdra, B. J. and Romp, W. E. (2008). A life-cycle overlapping-generations model of the small open economy. Oxford Economic Papers, 60:89-122.

Kotlikoff, L. J. and Spivak, A. (1981). The family as an incomplete annuities market. Journal of Political Economy, 89:372-391.

Leung, S. F. (1994). Uncertain lifetime, the theory of the consumer, and the life cycle hypothesis. Econometrica, 62:1233-1239. 
Leung, S. F. (2007). The existence, uniqueness, and optimality of the terminal wealth depletion time in life-cycle models of saving under uncertain lifetime and borrowing constraint. Journal of Economic Theory, 134:470-493.

Mitchell, O. S., Poterba, J. M., Warshawsky, M. J., and Brown, J. R. (1999). New evidence on the money's worth of individual annuities. American Economic Review, 89(5):1299-1318.

Pauly, M. V. (1974). Overinsurance and public provision of insurance: The role of moral hazard and adverse selection. Quarterly Journal of Economics, 88:44-62.

Romer, P. M. (1989). Capital accumulation in the theory of long-run growth. In Barro, R. J., editor, Modern Business Cycle Theory, pages 51-127. Basil Blackwell, Oxford.

Rothschild, M. and Stiglitz, J. (1976). Equilibrium in competitive insurance markets: An essay on the economics of imperfect information. Quarterly Journal of Economics, 90:629-649.

Saint-Paul, G. (1992). Fiscal policy in an endogenous growth model. Quarterly Journal of Economics, 107:1243-1259.

Sheshinski, E. (2008). The Economic Theory of Annuities. Princeton University Press, Princeton, NJ.

Walliser, J. (2000). Adverse selection in the annuities market and the impact of privatizing social security. Scandinavian Journal of Economics, 102:373-393.

Yaari, M. E. (1965). Uncertain lifetime, life insurance, and the theory of the consumer. Review of Economic Studies, 32:137-150. 


\section{CESifo Working Paper Series}

for full list see www.cesifo-group.org/wp

(address: Poschingerstr. 5, 81679 Munich, Germany, office@cesifo.de)

2837 Christoph Böhringer and Knut Einar Rosendahl, Green Serves the Dirtiest: On the Interaction between Black and Green Quotas, October 2009

2838 Katarina Keller, Panu Poutvaara and Andreas Wagener, Does Military Draft Discourage Enrollment in Higher Education? Evidence from OECD Countries, October 2009

2839 Giovanni Cespa and Xavier Vives, Dynamic Trading and Asset Prices: Keynes vs. Hayek, October 2009

2840 Jan Boone and Jan C. van Ours, Why is there a Spike in the Job Finding Rate at Benefit Exhaustion?, October 2009

2841 Andreas Knabe, Steffen Rätzel and Stephan L. Thomsen, Right-Wing Extremism and the Well-Being of Immigrants, October 2009

2842 Andrea Weber and Christine Zulehner, Competition and Gender Prejudice: Are Discriminatory Employers Doomed to Fail?, November 2009

2843 Hadi Salehi Esfahani, Kamiar Mohaddes and M. Hashem Pesaran, Oil Exports and the Iranian Economy, November 2009

2844 Ruediger Bachmann and Christian Bayer, Firm-Specific Productivity Risk over the Business Cycle: Facts and Aggregate Implications, November 2009

2845 Guglielmo Maria Caporale, Burcu Erdogan and Vladimir Kuzin, Testing for Convergence in Stock Markets: A Non-Linear Factor Approach, November 2009

2846 Michèle Belot and Jan Fidrmuc, Anthropometry of Love - Height and Gender Asymmetries in Interethnic Marriages, November 2009

2847 Volker Nitsch and Nikolaus Wolf, Tear Down this Wall: On the Persistence of Borders in Trade, November 2009

2848 Jan K. Brueckner and Stef Proost, Carve-Outs Under Airline Antitrust Immunity, November 2009

2849 Margarita Katsimi and Vassilis Sarantides, The Impact of Fiscal Policy on Profits, November 2009

2850 Scott Alan Carson, The Relationship between Stature and Insolation: Evidence from Soldiers and Prisoners, November 2009

2851 Horst Raff and Joachim Wagner, Intra-Industry Adjustment to Import Competition: Theory and Application to the German Clothing Industry, November 2009 
2852 Erkki Koskela, Impacts of Labor Taxation with Perfectly and Imperfectly Competitive Labor Markets under Flexible Outsourcing, November 2009

2853 Cletus C. Coughlin and Dennis Novy, Is the International Border Effect Larger than the Domestic Border Effect? Evidence from U.S. Trade, November 2009

2854 Johannes Becker and Clemens Fuest, Source versus Residence Based Taxation with International Mergers and Acquisitions, November 2009

2855 Andreas Hoffmann and Gunther Schnabl, A Vicious Cycle of Manias, Crashes and Asymmetric Policy Responses - An Overinvestment View, November 2009

2856 Xavier Vives, Strategic Supply Function Competition with Private Information, November 2009

2857 M. Hashem Pesaran and Paolo Zaffaroni, Optimality and Diversifiability of Mean Variance and Arbitrage Pricing Portfolios, November 2009

2858 Davide Sala, Philipp J.H. Schröder and Erdal Yalcin, Market Access through Bound Tariffs, November 2009

2859 Ben J. Heijdra and Pim Heijnen, Environmental Policy and the Macroeconomy under Shallow-Lake Dynamics, November 2009

2860 Enrico Spolaore, National Borders, Conflict and Peace, November 2009

2861 Nina Czernich, Oliver Falck, Tobias Kretschmer and Ludger Woessmann, Broadband Infrastructure and Economic Growth, December 2009

2862 Evžen Kočenda and Martin Vojtek, Default Predictors and Credit Scoring Models for Retail Banking, December 2009

2863 Christian Gollier and Martin L. Weitzman, How Should the Distant Future be Discounted when Discount Rates are Uncertain?, December 2009

2864 Tiberiu Dragu and Mattias Polborn, Terrorism Prevention and Electoral Accountability, December 2009

2865 Torfinn Harding and Beata Smarzynska Javorcik, A Touch of Sophistication: FDI and Unit Values of Exports, December 2009

2866 Matthias Dischinger and Nadine Riedel, There's no Place like Home: The Profitability Gap between Headquarters and their Foreign Subsidiaries, December 2009

2867 Andreas Haufler and Frank Stähler, Tax Competition in a Simple Model with Heterogeneous Firms: How Larger Markets Reduce Profit Taxes, December 2009

2868 Steinar Holden, Do Choices Affect Preferences? Some Doubts and New Evidence, December 2009 
2869 Alberto Asquer, On the many Ways Europeanization Matters: The Implementation of the Water Reform in Italy (1994-2006), December 2009

2870 Choudhry Tanveer Shehzad and Jakob De Haan, Financial Reform and Banking Crises, December 2009

2871 Annette Alstadsæter and Hans Henrik Sievertsen, The Consumption Value of Higher Education, December 2009

2872 Chris van Klaveren, Bernard van Praag and Henriette Maassen van den Brink, Collective Labor Supply of Native Dutch and Immigrant Households in the Netherlands, December 2009

2873 Burkhard Heer and Alfred Maußner, Computation of Business-Cycle Models with the Generalized Schur Method, December 2009

2874 Carlo Carraro, Enrica De Cian and Massimo Tavoni, Human Capital Formation and Global Warming Mitigation: Evidence from an Integrated Assessment Model, December 2009

2875 André Grimaud, Gilles Lafforgue and Bertrand Magné, Climate Change Mitigation Options and Directed Technical Change: A Decentralized Equilibrium Analysis, December 2009

2876 Angel de la Fuente, A Mixed Splicing Procedure for Economic Time Series, December 2009

2877 Martin Schlotter, Guido Schwerdt and Ludger Woessmann, Econometric Methods for Causal Evaluation of Education Policies and Practices: A Non-Technical Guide, December 2009

2878 Mathias Dolls, Clemens Fuest and Andreas Peichl, Automatic Stabilizers and Economic Crisis: US vs. Europe, December 2009

2879 Tom Karkinsky and Nadine Riedel, Corporate Taxation and the Choice of Patent Location within Multinational Firms, December 2009

2880 Kai A. Konrad, Florian Morath and Wieland Müller, Taxation and Market Power, December 2009

2881 Marko Koethenbuerger and Michael Stimmelmayr, Corporate Taxation and Corporate Governance, December 2009

2882 Gebhard Kirchgässner, The Lost Popularity Function: Are Unemployment and Inflation no longer Relevant for the Behaviour of Germany Voters?, December 2009

2883 Marianna Belloc and Ugo Pagano, Politics-Business Interaction Paths, December 2009 
2884 Wolfgang Buchholz, Richard Cornes and Dirk Rübbelke, Existence and Warr Neutrality for Matching Equilibria in a Public Good Economy: An Aggregative Game Approach, December 2009

2885 Charles A.E. Goodhart, Carolina Osorio and Dimitrios P. Tsomocos, Analysis of Monetary Policy and Financial Stability: A New Paradigm, December 2009

2886 Thomas Aronsson and Erkki Koskela, Outsourcing, Public Input Provision and Policy Cooperation, December 2009

2887 Andreas Ortmann, "The Way in which an Experiment is Conducted is Unbelievably Important": On the Experimentation Practices of Economists and Psychologists, December 2009

2888 Andreas Irmen, Population Aging and the Direction of Technical Change, December 2009

2889 Wolf-Heimo Grieben and Fuat Şener, Labor Unions, Globalization, and Mercantilism, December 2009

2890 Conny Wunsch, Optimal Use of Labor Market Policies: The Role of Job Search Assistance, December 2009

2891 Claudia Buch, Cathérine Tahmee Koch and Michael Kötter, Margins of International Banking: Is there a Productivity Pecking Order in Banking, too?, December 2009

2892 Shafik Hebous and Alfons J. Weichenrieder, Debt Financing and Sharp Currency Depreciations: Wholly vs. Partially Owned Multinational Affiliates, December 2009

2893 Johannes Binswanger and Daniel Schunk, What is an Adequate Standard of Living during Retirement?, December 2009

2894 Armin Falk and James J. Heckman, Lab Experiments are a Major Source of Knowledge in the Social Sciences, December 2009

2895 Hartmut Egger and Daniel Etzel, The Impact of Trade on Employment, Welfare, and Income Distribution in Unionized General Oligopolistic Equilibrium, December 2009

2896 Julian Rauchdobler, Rupert Sausgruber and Jean-Robert Tyran, Voting on Thresholds for Public Goods: Experimental Evidence, December 2009

2897 Michael McBride and Stergios Skaperdas, Conflict, Settlement, and the Shadow of the Future, December 2009

2898 Ben J. Heijdra and Laurie S. M. Reijnders, Economic Growth and Longevity Risk with Adverse Selection, December 2009 